\title{
MRI Brain Lump Based on Consistency Feature and Classification using Neural Network
}

\author{
Mohanraj.R, Ramya, Hema.
}

\begin{abstract}
MRI brain tumor image are segmented using texture feature and Artificial Neural Network are used for taxonomy. The proposed system uses ROI, seed selection and cellular automata based grow cut method for segmentation. The selection based on energy and entropy quality of Grey echelon Co-occurrence matrix, then Long run emphasis and Run length non homogeny is compared with Co-occurrence feature to get a feasible seed point from abnormal region. With this seed point cellular automata based grow cut method is proposed for segmenting the tumor region from MRI image. Morphological process is the smoothing process applied on obtained tumor part for highlighting it by removing distortion, noise and coarse region. By means of the Radial basis occupation of Artificial Neural Network which was accuracy, the tumor part is classified into normal, benign and malignant.
\end{abstract}

Keywords :Feature extraction, grey level co-occurrence matrix, Run Length features, seed point selection, grow cut method, cellular automata.

\section{INTRODUCTION}

Alluring Resonance picture division is an essential issue in helpful picture examination and observation in light of the way that these photos contain strong spot fusses and diminishing collectibles. These systems can be addressed these approaches, edge based methodology, limit based strategies, locale based procedures, mix frameworks that merged breaking point and territory criteria and dynamic shape based philosophies [5]The half and half systems [4] depend on the blend of Boundary and locale based division. In spite of the fact that it produces shut limits, it experiences trouble, if there is noise and indistinct boundaries in between the two adjacent regions.[7-15]

\section{METHODOLOGY}

Every pixel in the ROI is handled and two highlights: co-event and Run length highlights are separated individually;

Revised Manuscript Received on August 22, 2019

Mohanraj.R Assistant Professor, Department of Electronics And Communication Engineering,, Bharath Institute of Higher Education and Research, Chennai, India. dspmohanraj@gmail.com

Ramya ,Assistant Professor, Department of Electronics And Communication Engineering,, Bharath Institute of Higher Education and

Hema,Assistant Professor, Department of Electronics And Communication Engineering,, Bharath Institute of Higher Education and Research, Chennai, India. Research, Chennai, India .

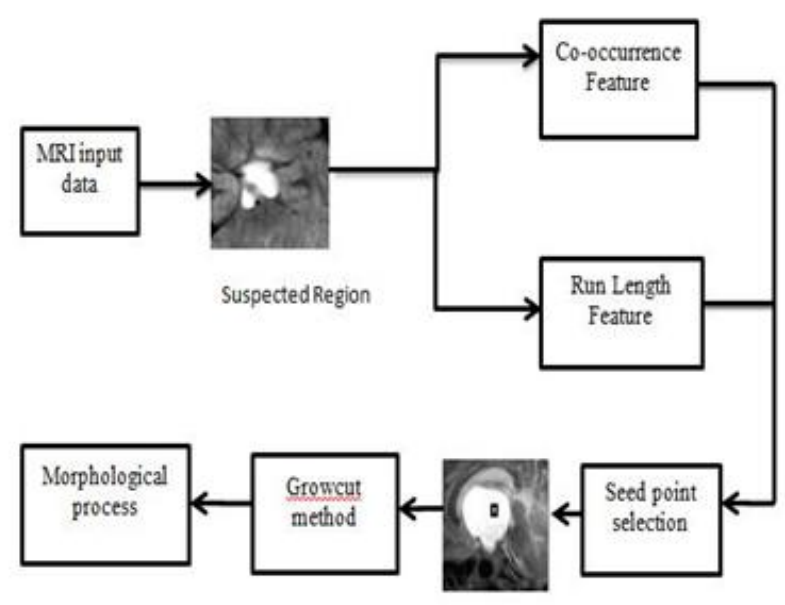

Fig. 1 System Diagram

\section{A.Co-Occurrence Matrix Probability Features}

A COM is in this manner a square framework that has the span of the biggest pixel esteem in the picture and exhibits the relative recurrence disseminations of dim dimensions and depict how regularly one dark dimension will show up in a predefined spatial relationship to another dim dimension inside each picture locale.[16-20]

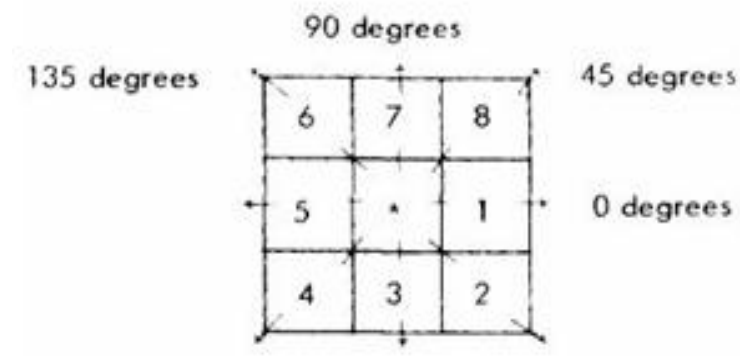

Fig. 2: Co-occurrence matrixes with its orientations

There are 14 features that may be extracted from COM matrix [8] but 2 textural features were calculated from the COM The matrix was normalized by the following function: For instance; with a 8 dim dimension picture portrayal and a vector $\mathrm{t}$ that thinks about just a single neighbor,

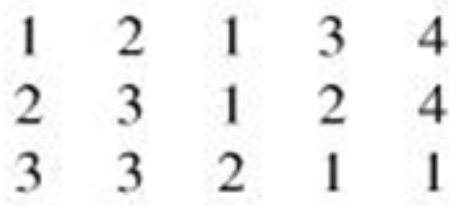

Fig. 3 Image examples for co-occurrence matrix

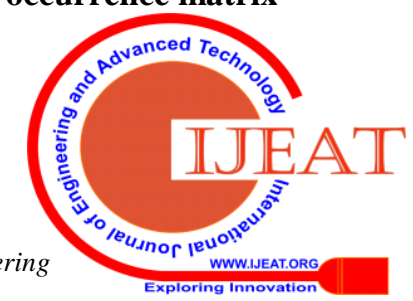




\begin{tabular}{c|c|cc|c|c|c|c|c} 
& 0 & 1 & 2 & 3 & 4 & 5 & 6 & 7 \\
\hline 0 & 0 & 0 & 0 & 0 & 0 & 0 & 0 & 0 \\
\hline 1 & 0 & 1 & 2 & 0 & 0 & 0 & 0 & 0 \\
\hline 2 & 0 & 1 & 0 & 2 & 0 & 0 & 0 & 0 \\
\hline 3 & 0 & 0 & 1 & 1 & 0 & 0 & 0 & 0 \\
\hline 4 & 0 & 1 & 0 & 0 & 1 & 0 & 0 & 0 \\
\hline 5 & 0 & 0 & 0 & 0 & 0 & 0 & 0 & 0 \\
\hline 6 & 0 & 0 & 0 & 0 & 0 & 0 & 0 & 0 \\
\hline 7 & 0 & 0 & 0 & 0 & 0 & 0 & 0 & 0
\end{tabular}

Fig. 4 Classical Co-occurrence matrix

\section{B. Energy}

Imperativeness is called Angular Second Moment. It is a measure the homogeneousness of the image and can be resolved from the institutionalized COM. It is a fitting measure for disclosure of perplexity in surface picture. Higher characteristics for this component infer that less changes in the image adequacy or power result in a much sparser COM. The vitality is planned by the accompanying condition

$$
J=\sum_{i=1} \sum_{j=1}(p(i, j))^{2}
$$

\section{C.Entrop}

$$
S=-\sum_{i=1} \sum_{j=1} p(i, j) \log (p(i, j))
$$

The estimation of essentialness and entropy are high for homogeneous regions and low for non-homogeneous territories. The uncommon area in the ultrasound pictures radiates an impression of being homogeneous. So these parameters can perceive a seed pixel from the irregular zones. A couple of cases the seed pixel is browsed the run of the mill region which has every one of the reserves of being homogeneous [9].

Attractive Resonance picture division is a basic issue in restorative picture investigation and perception in light of the fact that these pictures contain solid spot clamors and lessening antiques.

These strategies can be spoken to these methodologies, edge based procedure, limit based techniques, district based techniques, blend systems that consolidated limit and area criteria and dynamic shape based methodologies. Limit strategy utilizes just dim dimension data and don't think about the spatial data of the pixels and don't oversee well with clamor or poor limits which for the most part experienced in ultrasound pictures.

Run length features rely upon count of relentless probability of the length and diminish measurement of the rough in the surface. After the assurance of seed pixel from co-occasion features, we can check whether the picked seed pixel has a spot

\section{Gray Level Run Length Features}

\section{E.Long Run Emphasis}

The LRE is exceedingly rely upon the event of long runs and is normal vast for coarse auxiliary surfaces [10].

$$
\frac{\sum_{i=1}^{G} \sum_{j=1}^{R} j^{2} p(i, j)}{\sum_{i=1}^{G} \sum_{j=1}^{R} p(i, j)}
$$

\section{F. Run Length Non UniformitY}

Measure the comparability of the length of keeps running all through the picture. The RLN is low if the run lengths are indistinguishable all through the picture.

$$
\frac{\sum_{i=1}^{G} \sum_{j=1}^{R} j p(i, j)^{2}}{\sum_{i=1}^{G} \sum_{j=1}^{R} p(i, j)}
$$

$\mathrm{p}(\mathrm{i}, \mathrm{j})$ is srun length matrix,

\section{G.denotes number of gray levels, $\mathbf{R}$ is longest run.}

In the event that all the run length highlights of chosen point and its neighborhood focuses are equivalent then the fact of the matter is considered as a seed point.

\section{H.Dataset Images}

The quantity of ROIs for Normal district are taken altogether expansive than the anomalous areas to well perceive exceedingly changing anatomical locales. All photos are gotten using a comparable MRI gear. These tumors are looked into and physically separated by the radiologists reliant on their knowledge on visual picture interpretation of cerebrum tumors, clinical history of the patient, and disorder confirmation by the biopsy/dynamic helical CT/MRI/hypochondriac examinations

\section{Seed point selection}

Stage 1: From the MRI mind tumor picture crop the unusual area physically and discover co-event lattice and relating highlights for every window and store the qualities.

Stage 2: The normal of least and most extreme estimations of both vitality and Entropy is found.

Stage 3: Select the focuses which have the component esteems between the most extreme esteem and the normal estimation of least and greatest qualities.

Stage 4: Calculate the run length highlights for chosen focuses and their neighborhood focuses utilizing long run accentuation and run length non consistency.

Stage 5: Select the point as a seed point if all the run length highlights of chosen focuses and its neighborhood focuses are equivalent.

Stage 6: Perform the cell automata based develop cut technique from the got seed point for fragmenting the tumor part [9] [11]. 


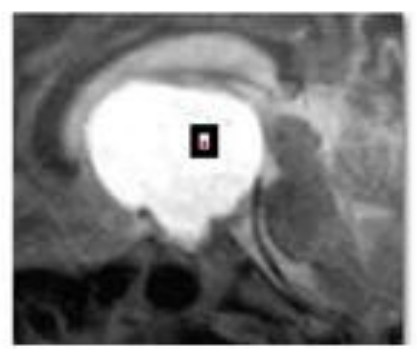

Fig. 5 Data set for input image J. Cellular Automata Based Segmentation

A phone machine is fundamentally a PC calculation that is discrete in existence and works on a grid of cells. Cell Automata has pulled in specialists from different fields in both physical and sociologies as a result of its straightforwardness, and potential in demonstrating complex frameworks. Every individual cell is in a particular state and changes synchronously relying upon the conditions of a few neighbors as controlled by a nearby refresh rule. is the neighborhood; $\mathrm{SN}$,

\section{K.CA Based Grow Cut Algorithm}

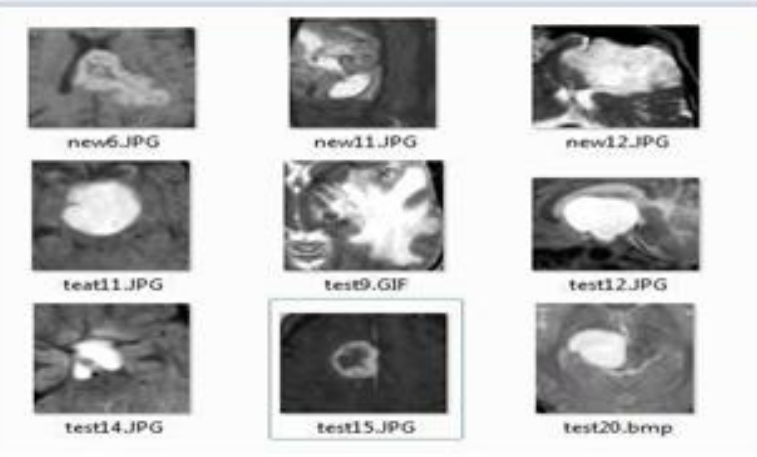

Fig. 6 Selection of seed point coordinates

Develop Cut is an intuitive division calculation. It utilizes cell automata as a picture display. Automata development models division process. In this develop cut strategy; Second slice the histogram from MAX to 0 . At that point discover the edge from MAX to the most elevated power which isolates the vulnerability. This is basically done utilizing the outstanding strategy. Ideal edge esteem is the esteem that can make a stop to the district developing and the got locale is ideal. It is attractive that the edge esteem is sufficiently high to separate the entire area, yet on the off chance that the edge esteem is higher than the ideal one, the extricated locale may develop over the real district limit and develop to an a lot bigger district. In like manner the tumor part is separated from the anomalous area.

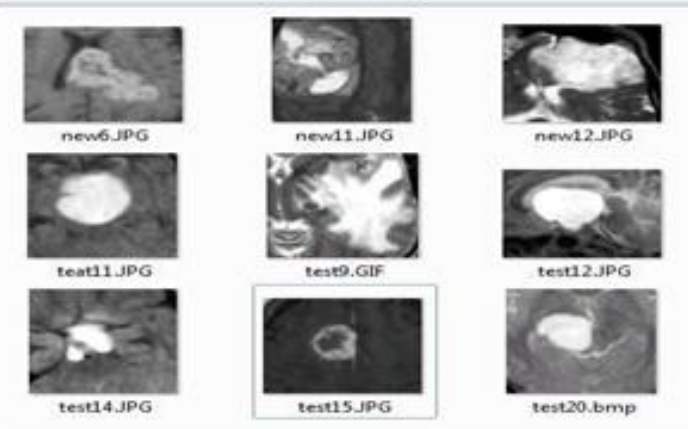

Fig. 7 segmentation of tumor part

\section{Morphological Process}

Morphology is a far reaching course of action of picture taking care of exercises that strategy pictures reliant on shapes.

1) The Canny Edge Detection

The algorithm runs in 5 separate steps

Run length highlight is contrasted and the co-event strategy and observed to be an achievable surface element in organ division .Grow slice division to segment the tumor hankie supplementary into its necrotic and improving parts and Strengths the proposed technique which incorporates straightforward connection over a solitary cut and less affectability

2) Erosion And Dilation

In the morphological expansion and disintegration activities, its neighbors in the information picture [11] [12].

Following figure represents the Canny edge discovery strategy is utilized for distinguishing the edge and pixels are included at the limit area dependent on expansion procedure and tumor is extricated.
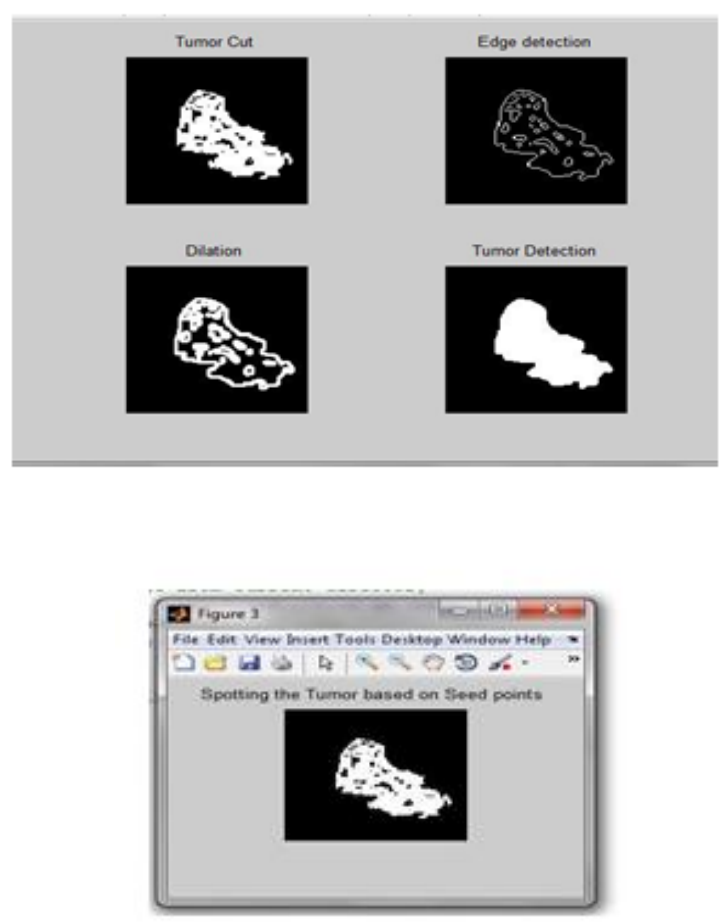

Fig. 8 Morphological operation and edge detection

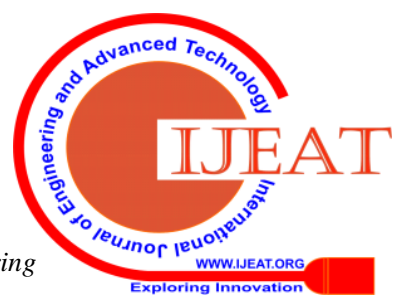




\section{CONCLUSION}

Division calculation for the issue of tumor outline which show fluctuating tissue qualities was proposed .As the revolutionize in necrotic and improving piece of the tumor after emission treatment ends up vital, Texture include investigation dependent on Gray dimension co-event lattice is connected. Run length highlight is contrasted and the co-event strategy and observed to be an achievable surface element in organ division .Grow slice division to segment the tumor hankie supplementary into its necrotic and improving parts and Strengths the proposed technique which incorporates straightforward connection over a solitary cut and less affectability to the introduction (shown by lower coefficient of variety esteems), its productivity regarding calculation time, and power as for various and heterogeneous tumor types. The advantage of this calculation is as per the following: it gives a sans parameter condition to permit least client intercession. This can be particularly useful for bunch effort for creation category runs or learner PC user's radiologist

\section{FUTURE WORK}

This paper can be reached out by utilizing probabilistic Neural Network which gives quick and exact order results than supplementary neural systems and it is a capable device for characterization of the MRI Brain tumors in stage two and FCM based bunching calculation is utilized for dividing the threatening tumor which is the most quick dependable and produces the precise outcomes than Grow cut calculation or some other technique.

\section{REFERENCES}

1. Kongkham, D. \& Sundararajan, M. 2019, "Distributed wideband sensing method for faded dynamic spectrum access", International Journal of Innovative Technology and Exploring Engineering, vol. 8, no. 10, pp. 4309-4312.

2. Balaji, S., John Paul Praveen, A. \& Mohanraj, R. 2019, "Recognizable proof and analysis of palm print in biometric authentication system using bayes techniques", International Journal of Innovative Technology and Exploring Engineering, vol. 8, no. 9 Special Issue 3, pp. 1126-1129.

3. Kavitha, G., Priya, N., Velvizhi, R. \& Allin Geo, A.V. 2019, "Parallel computation in correspondence and signal processing", International Journal of Innovative Technology and Exploring Engineering, vol. 8, no. 9 Special Issue 3, pp. 1136-1139.

4. Hema, R., Sundararajan, M. \& Balaji, S. 2019, "Smartphone control robot with automatic firing gun", International Journal of Innovative Technology and Exploring Engineering, vol. 8, no. 9 Special Issue 3, pp. 625-627.

5. Kaliyamurthie, K.P., Sundar Raj, B., Velvizhi, R. \& Shanmugapriya, K. 2019, "Dual band paper substrate CPW antenna for wireless applications", International Journal of Innovative Technology and Exploring Engineering, vol. 8, no. 9 Special Issue 3, pp. 605-608.

6. Geo, A.V.A., Arunachalam, A.R., Michael, G. \& Elankavi, R. 2019, "Evaluating architecture using compact modalities", International Journal of Innovative Technology and Exploring Engineering, vol. 8, no. 9 Special Issue 3, pp. 836-838.

7. Theivasigamani, S., Jeyapriya, D. \& Anita Davamani, K. 2019, "Anamoly analyzing and exploring for wireless sensor networks", International Journal of Innovative Technology and Exploring Engineering, vol. 8, no. 9 Special Issue 3, pp. 1116-1118.

8. Jeyapriya, D., Theivasigamani, S., Velvizhi, R. \& Nandhini, P. 2019, "Program detection in wireless feeler networks", International Journal of Innovative Technology and Exploring Engineering, vol. 8, no. 9 Special Issue 3, pp. 1194-1195.

9. Gowri Sankaran, B., Karthik, B. \& Vijayaragavan, S.P. 2019, "Image compression utilizing wavelet transform", International Journal of
Innovative Technology and Exploring Engineering, vol. 8, no. 10, pp. 4305-4308

10. Gowri Sankaran, B., Karthik, B. \& Vijayaragavan, S.P. 2019, "Weight ward change region plummeting change for square based image huffman coding", International Journal of Innovative Technology and Exploring Engineering, vol. 8, no. 10, pp. 4313-4316.

11. Hema, R., Sundararajan, M. \& Balaji, S. 2019, "Smartphone control robot with automatic firing gun", International Journal of Innovative Technology and Exploring Engineering, vol. 8, no. 9 Special Issue 3, pp. 625-627.

12. Rangaswamy, K. \& Rajabhushanam, C. 2019, "Congestion control in wireless network using TCP friendly rate control (TFRC)", International Journal of Recent Technology and Engineering, vol. 8, no. 2 Special issue 3, pp. 1598-1602.

13. Tamil Selvan, S. \& Sundararajan, M. 2019, "Performance Parameters of 3 Value $8 \mathrm{t}$ Cntfet Based Sram Cell Design Using H-Spice", International Journal of Recent Technology and Engineering, vol. 8, no. 2 Special issue 5, pp. 22-27.

14. Vinoth, V.V. \& Kanniga, E. 2019, "Steganographical techniques in hiding text images - system", International Journal of Recent Technology and Engineering, vol. 8, no. 2, pp. 6535-6537.

15. Saravana, S., Balaji, S., Arulselvi, S. \& John Paul Praveen, A. 2019, "Reliable power quality monitoring and protection system", International Journal of Innovative Technology and Exploring Engineering, vol. 8, no. 9 Special Issue 3, pp. 644-645.

16. Sundaramoorthy, A. \& John Wiselin, M.C. 2019, "Single patch antenna with multiple feed", International Journal of Innovative Technology and Exploring Engineering, vol. 8, no. 9, pp. 1743-1747.

17. Velavan, R., Bharanidharan, S. \& Sheeba, B. 2019, "EMF pollution Causes, effects and protection", International Journal of Innovative Technology and Exploring Engineering, vol. 8, no. 9 Special Issue 3, pp. 1166-1168

18. Veer, R.A., Arulselvi, S. \& Karthik, B. 2019, "Construction of ensemble square classification approaches in MIMO OFDM", International Journal of Engineering and Advanced Technology, vol. 8, no. 5, pp. 2039-2041.

19. Agitha, W. \& Kaliyamurthie, K.P. 2019, "Improved energy efficient in WBAN using MAC with cloud computing", International Journal of Innovative Technology and Exploring Engineering, vol. 8, no. 8, pp. 2405-2408

20. Kastro, G.G. \& Wiselin, M.C.J. 2019, "Design and analysis of stub loaded resonator", International Journal of Recent Technology and Engineering, vol. 8, no. 1 Special Issue4, pp. 272-283.

\section{AUTHORS PROFILE}

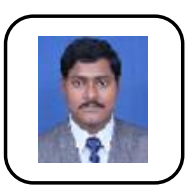

Mohanraj.R Assistant Professor, Department of Electronics And Communication Engineering,, Bharath Institute of Higher Education and Research, Chennai, India.

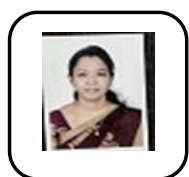

Ramya ,Assistant Professor, Department of Electronics And Communication Engineering,, Bharath Institute of Higher Education and Research, Chennai, India

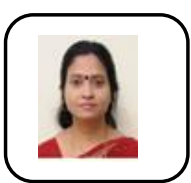

Hema, Assistant Professor, Department of Electronics And Communication Engineering, Bharath Institute of Higher Education and Research, Chennai, India. 